\title{
Presence or Absence of Earlobes Reveals Different Biometric Structure among the Peluca Hen from Guatemala
}

\author{
Pere M. Parés-casanova ${ }^{1^{*}}$ and Raúl Jáuregui ${ }^{2}$ \\ ${ }^{1}$ Departament de Ciència Animal, ETSEA, Universitat de Lleida, Av. Rovira Roure 191, 25198 Lleida, \\ Catalonia, España, Spain. \\ ${ }^{2}$ Institute de Investigación, Centro Universitario de Oriente (CUNORI), Universidad de San Carlos de \\ Guatemala, Guatemala.
}

Authors' contributions

This work was carried out in collaboration between both authors. Both authors interpreted the data, critically revised the manuscript for important intellectual contents and approved the final version.

Article Information

DOI: $10.9734 / A R R B / 2021 / v 36 i 330356$

Editor(s):

(1) Dr. Md. Torequl Islam, Federal University of Piaui, Brazil.

Reviewers:

(1) Jibril Lawal, Federal University Gusau, Nigeria.

(2) Fábio Loures Cruz, Federal University of Lavras, Brazil.

Complete Peer review History: http://www.sdiarticle4.com/review-history/61481

Original Research Article

Received 23 July 2020

Accepted 28 September 2020

Published 17 April 2021

\section{ABSTRACT}

Background and Objective: Earlobe, a head furnishing trait, is a non-putative trait in Peluca hen ("naked-necked" hen), a local breed from Guatemala. The objective of this study is to determine if presence or absence of earlobe is linked to a body linear trait.

Materials and Methods: Quantitative data collected on 311 mature hens belonging to Peluca breed were subjected to analyses for two different phenotypic subsets according to presence/absence of earlobes (212 with earlobes and 99 without earlobes). Measured morphometric traits were 18: Weight, Perimeter, Length, Width and Height of Body, Wing Length, Leg Length, Lengths of Head, Beak and Face, Length and Width of Shank, Metatarsal Perimeter, Dorso-sternal Height, Bicostal Length, Withers Height, and Thoracic and Abdominal Perimeters. A Principal Component Analysis was applied to the study of variable between both groups to explore the relationship between traits. Results: body length and height, and abdominal and thoracic perimeters were the most discriminative traits between groups. "Non-lobe" group presented significative higher values only for body length. 
Conclusion: Presence/absence of earlobes describe a different body structure within the Peluca hen. Moreover, as this represents no adaptative response, presence or absence of earlobe must be considered to be more related to the productive aptitude rather than different ecotypes. This association of earlobe with some body traits is important since it can ease the task of selecting productive characteristics of the "Peluca" hen.

Keywords: Biotype; body linear measurement; body weight; creole; local breeds.

\section{INTRODUCTION}

Morphometry can be used to develop breeding strategies via optimization of body traits to achieve maximum performances and economic returns $[1,2,3]$. Body measurements, which give significant information on morphologic structure and development ability of animals, are influential factors on determining animals that are appropriate for the desired efficiency $[1,2,3]$. The phenotypic information can serve also as a basis for designing appropriate conservation, breeding and selection strategies [4]. In this regard, several authors point out that the use of multivariate analysis tools can be especially useful for describing local animal populations, allowing them to be managed as specific genetic resources $[1,2,5]$.

South and Mesoamerican livestock are still largely in the hand of smallholders. Native chickens possess several valuable characters that are not found in exotic (commercial) chickens and are totally appropriate for traditional low input-low output traditional farming systems. The genetic resource base of indigenous chicken in Mesoamerican countries is rich and form the basis for genetic improvement and development of locally adapted breeds [6,7]. Characterization of these indigenous animal resources is a necessary pre-requisite for indigenous breed development and improvement of rural poultry $[1,8,3]$. Non artificial selection of traits in villages has been provided a unique and powerful resource for phenetic diversity [7], such diversity being important to survive in resource-limited production systems with hostile environmental settings $[9,10]$. So native breeds provide a unique food resource to respond to the present and future needs of livestock production in lowinput countries $[9,10]$. In this sense, the costs and poor adaptation associated to exotic chicken has been a fortunate barrier for their introduction into the rural production.

Local chicken breeds are very important because of many valuable characteristics such as diseases resistance, production in harsh environment, ability to use low quality forage and cultural values $[1,2,5]$. So, without plans to improve and strengthen the current conservation activities, there could be risk of extinction leading to total loss of this genetic material. Guatemala is characterized by the coexistence of two production systems: rudimentary village poultry and industrial poultry at its infancy, the latter facing scarcity of inputs to fully be exploited.

This study was conducted to measure body weight and morphometric traits of Peluca hen ("naked-necked" hen), a native population from Guatemala [11] which is not recognized officially, although many researches has been done on it [5]. Peluca hen is characterized by a very variable phenotypic landscape, showing striking morphological variations in plumage colour and pattern, comb shape, earlobe presence, skin and wattles colour, etc. [11,5], although she is always naturally devoid of feathers on its neck and vent. Peluca presents both and 'Asiatic' conformation as 'Mediterranean' features [11]. Mallia [11] offers an exhaustive description of this hen and the management system. Normally chicken of different types subsist on scavenging and mating is uncontrolled and random [11]. Animals are good scavengers as well as foragers, have good maternal qualities, and are hardier when compared to the exotic breeds, having also high survival rates with minimal care and attention [11].

Peluca breed has a high potential for improving the standard of living and the nutritional needs among the rural Guatemala habitants. This rural poultry in the area of study represents a promising extensive or scavenging management system. Hence determining the knowledge of body measurements may have an interest in improving breed knowledge appropriately. The earlobe is a feather-bared structure on the skin of the face just below the ear, the outline of which is marked by a slight thickening of the tissues [12]. As a part of skin structure on the face without feathers and below the ear, earlobe is a conspicuous trait [13]. In any case, plumage patterns (with at least 8 different colour patterns) 
have not been considered, as we think that their selection are interesting only for poultry fanciers and so merely linked to mere ring competitions.

The objective of this study is to determine if presence or absence of earlobe are correlated to body linear traits. Understanding the relationship among traits is very important since traits are able to influence the preference of the consumers and market price as well [14]. The information to be gained in the study will be especially helpful in planning future breeding programs and conservation strategies of prospective local chicken biotypes, especially addressed to local communities.

\section{MATERIALS AND METHODS}

\subsection{Sampling Procedure}

Data collection was carried out during 2019 in different indigenous communities from Jocotán, Camotán, San Juan Ermita and Olopa municipalities, in the Mayan Ch'orti region in Chiquimula, Southeastern Guatemala. Purposive sampling was used to select wards and villages with large numbers of local chickens based on the information. A final sample of 311 mature females (212 with earlobes and 99 without earlobes) was studied. Presence or absence of earlobe was assessed visually and registered.

\subsection{Data Collection}

Measures of live weight and morphometric traits were taken using a weighing scale and a measuring tape. The measured morphometric traits were 18, some of them of economic importance: Weight (BOW), Perimeter (BOPE), Length (BOL), Width (BOWD) and Height $(\mathrm{BOH})$ of body, Wing Length (WIL), Leg Length (LEL), Lengths of Head (HDL), Beak (BEL) and Face (FAL), Length (SHL) and Width (SHW) of Shank, Metatarsal Perimeter (MTP), Dorso-Sternal Height (DEH), Bicostal Length (BIL), Withers Height (WIH), and Thoracic (THP) and Abdominal Perimeters (ABP), following common biometrical procedures described in detail in previous works $[15,16,3]$. Data were taken using a plastic rule, calliper and flexible to measure linear traits whereas a weighing scale was used to determine live body weight. Data are available upon request to first author.

\subsection{Statistical Analysis}

One-way Non-Parametric Multivariate Analysis of Variance (NPMANOVA) using Mahalanobis distances (Bonferroni p-corrected values) was applied for multivariate comparison, while MannWhitney $U$ test was used for univariate comparison. A between-groups Principal Component Analysis (PCA) from var-covar matrix were conducted. PCA is a multivariate technique used mainly to reduce the dimensionality of data and to explore the relationship between traits in a dataset. This analysis aimed to find a way to condense (summarize) the information contained in several original variables into a smaller set of new composite dimensions or variants with a minimum loss of information. Statistical procedures were done with software PAST v. 2.17c [17] with the significance level established at 0.05 .

\section{RESULTS AND DISCUSSION}

One-way NPMANOVA reflected highly significative statistical differences between two groups $(F=4.151, p=0.0001)$. They indicate the existence of two subsets within the Peluca population, with some different architectural patterns between lobed and non-lobed animals.

In PCA, first two Principal Components explained a $60.2 \%$ of the total observed variance (Fig. 1 and Table 1). As there appeared only positive

Table 1. Eigenvalues for principal components (PC) in the principal component analysis from var-covar matrix in a sampling of 311 females (212 with earlobes and 99 without earlobes)

\begin{tabular}{llll}
\hline PC & Eigenvalue & $\begin{array}{l}\% \\
\text { variance }\end{array}$ & $\begin{array}{l}\text { \% cumulative } \\
\text { variance }\end{array}$ \\
\hline 1 & 30.3379 & 36.7440 & 36.7440 \\
2 & 19.3420 & 23.4260 & 60.1700 \\
3 & 11.6210 & 14.0750 & 74.2450 \\
4 & 5.7301 & 6.9401 & 81.1851 \\
5 & 4.5161 & 5.4698 & 86.6549 \\
6 & 2.7103 & 3.2826 & 89.9375 \\
7 & 2.3149 & 2.8038 & 92.7413 \\
8 & 1.7620 & 2.1341 & 94.8754 \\
9 & 1.1359 & 1.3758 & 96.2512 \\
10 & 0.9852 & 1.1932 & 97.4444 \\
11 & 0.6997 & 0.8475 & 98.2919 \\
12 & 0.5329 & 0.6454 & 98.9373 \\
13 & 0.3212 & 0.3890 & 99.3264 \\
14 & 0.2109 & 0.2554 & 99.5818 \\
15 & 0.1645 & 0.1993 & 99.7811 \\
16 & 0.0714 & 0.0865 & 99.8675 \\
17 & 0.0656 & 0.0794 & 99.9469 \\
18 & 0.0431 & 0.0522 & 99.9991 \\
\hline
\end{tabular}


loadings (Fig. 2) traits are referred to size. Most discriminative traits were Body Length $(\mathrm{BOL})$ and Height $(\mathrm{BOH})$, and Abdominal (ABP) and Thoracic (THP) Perimeters (Table 2), which jointly differentiated both groups $(\mathrm{F}=5.06$, $p=0.0005$ ).

Separately, only thoracic perimeter showed no statistical differences $(U=9818, p=0.357)$ (Fig. 3). Thus, body length, body height and abdominal perimeter represent a different potential selection criterium considered separately (Table 3 ), the two later being higher in eared group. Thus, it would be possible that presence/absence of earlobes describe different morphologies within the in the Peluca hen. Traits can be considered not to be adaptive, so it is possible to select different bodied animals according to presence/absence of earlobes, which can be clearly seen, and not using empirical points. As management is always identical for all animals (keepers do not play attention to this character) it can be supposed we cannot differentiate two different biotypes. The association among characters is important since it eases the task of describing the phenotypic characteristics of selection groups in particular combinations [14].
Table 2. Loadings for two first principal components, which explained a $60.2 \%$ of the total observed variance. Most discriminate traits $(>[0.3])$ appear in bold. Most discriminative traits were Body Length (BOL) and Height (BOH), and Abdominal (ABP) and Thoracic (THP) Perimeters

\begin{tabular}{lll}
\hline & PC1 & PC2 \\
\hline ABP & 0.3631 & 0.6646 \\
BeL & 0.0202 & 0.0133 \\
BIL & 0.0652 & 0.1176 \\
BoH & 0.3604 & 0.0371 \\
BoL & 0.6224 & -0.6462 \\
BoP & 0.2510 & 0.0979 \\
BoW & 0.0392 & 0.0535 \\
DEH & 0.0525 & 0.0522 \\
FAL & 0.0581 & 0.0102 \\
HdL & 0.0476 & 0.0118 \\
HdW & 0.0272 & -0.0063 \\
LeL & 0.1254 & -0.0389 \\
MTP & 0.0479 & 0.0207 \\
SHL & 0.0979 & -0.0089 \\
SHW & 0.0196 & 0.0897 \\
ThP & $\mathbf{0 . 3 1 3 7}$ & 0.2635 \\
WIH & 0.2966 & 0.1585 \\
WIL & 0.2411 & -0.0726 \\
\hline
\end{tabular}

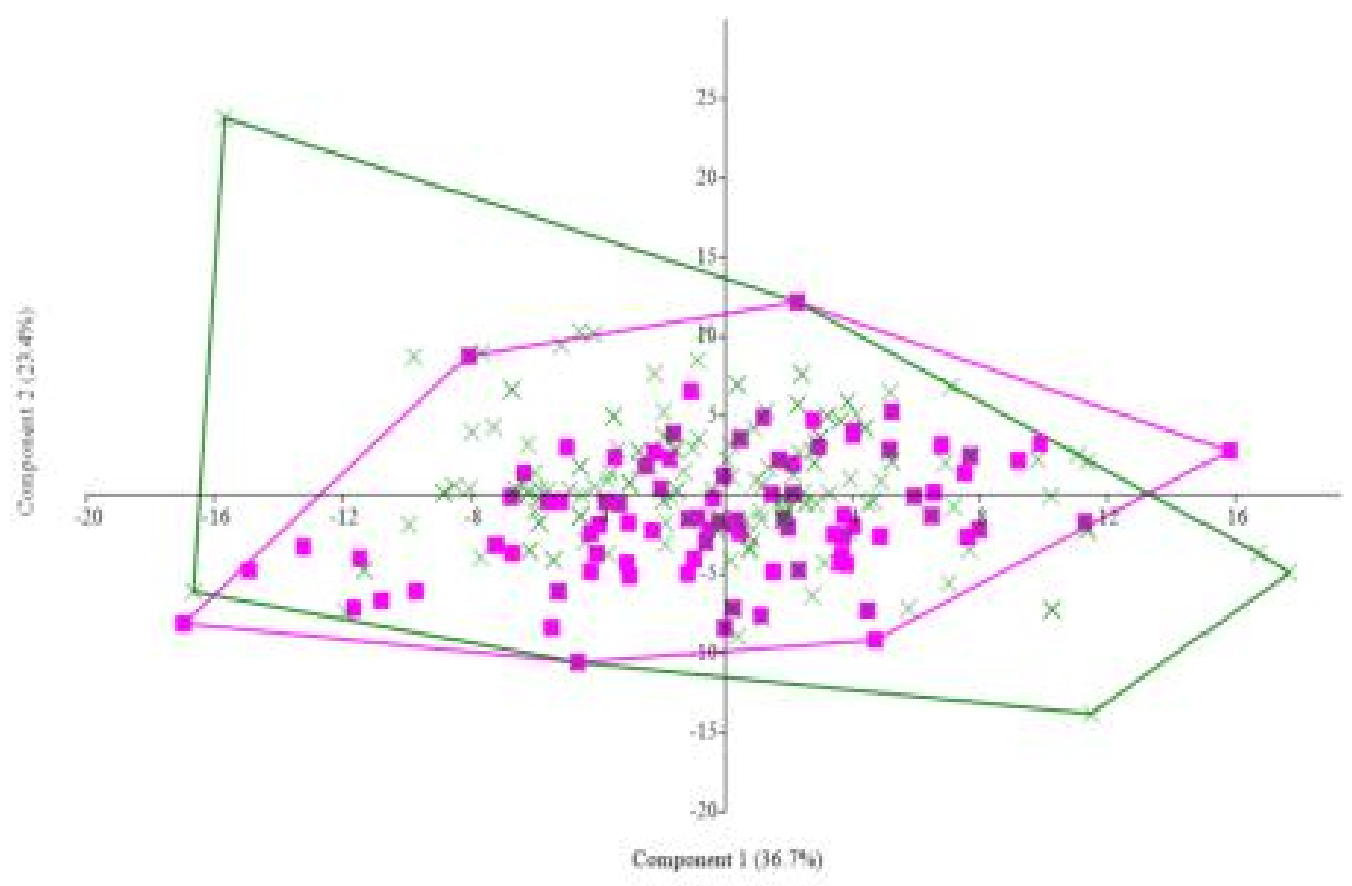

Fig. 1. Principal component analysis from var-covar matrix in a sampling of $\mathbf{3 1 1}$ females $\mathbf{2 1 2}$ with earlobes $x$ and 99 without earlobes $q$ of Peluca hens. First two principal components explained a $60.2 \%$ of the total observed variance 


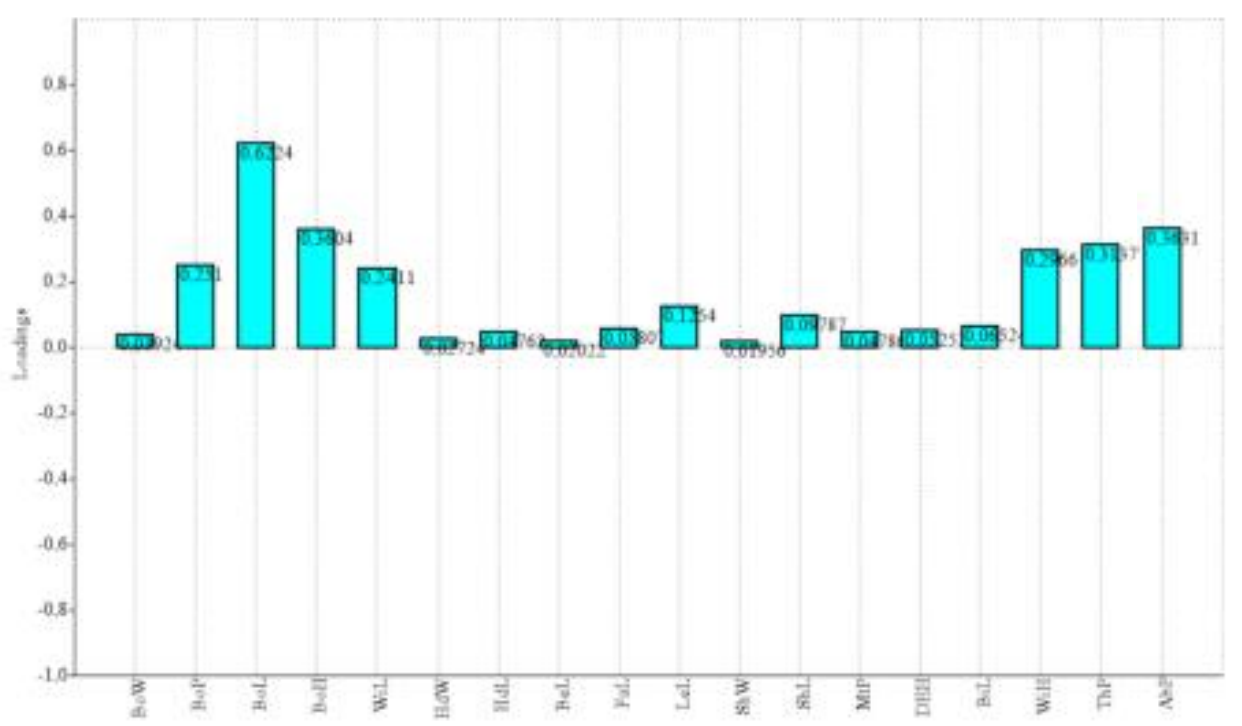

Fig. 2. Loadings for Principal Component 1 which explained a $36.7 \%$ of the total observed variance. The measured morphometric traits were 18: Weight (BOW), Perimeter (BOPE),

Length (BOL), Width (BOWD) and Height (BOH) of body, Wing Length (WIL), Leg Length (LEL), Lengths of Head (HDL), Beak (BEL) and Face (FAL), Length (SHL) and Width (SHW) of Shank, Metatarsal Perimeter (MTP), Dorso-Sternal Height (DEH), Bicostal Length (BIL), Withers Height (WIH), and Thoracic (THP) and Abdominal Perimeters (ABP). Most discriminative traits were Body Length (BOL) and Height (BOH), and Abdominal (ABP) and Thoracic (THP) Perimeters

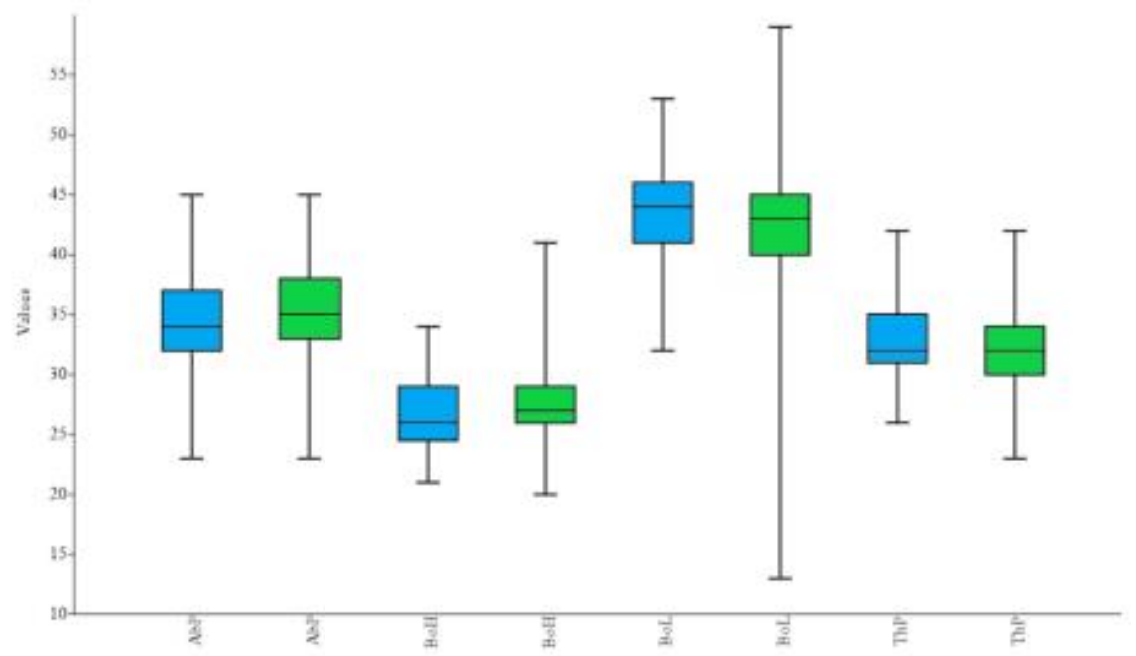

Fig. 3. Box-whisker diagram for the values of length of body length (BOL) and height (BOH), abdominal (ABP) and thoracic (THP) perimeters. Only thoracic perimeter showed no statistical differences $(U=9818, p=0.357)$ for non-earlobe (blue, $n=99)$ and earlobe (green, $n=212)$ groups. Each rectangle is divided by a horizontal segment indicating where the median is positioned. The whiskers have an extension limit, which in the case under study did not present any outof-range data. Non-earlobe group presented higher values only for length of body 
Table 3. Main descriptive statistics for abdominal perimeter, body height and body length between non-earlobe $(n=99)$ and earlobe $(n=212)$ groups, the two later being higher in eared group. Measurement in $\mathrm{cm}$, except for coefficient of variation (\%)

\begin{tabular}{|c|c|c|c|c|c|c|}
\hline & $\begin{array}{l}\text { Non- } \\
\text { Ear-lobe }\end{array}$ & Ear-lobe & $\begin{array}{l}\text { Non- } \\
\text { Ear-lobe }\end{array}$ & Ear-lobe & $\begin{array}{l}\text { Non- } \\
\text { Ear-lobe }\end{array}$ & Ear-lobe \\
\hline & $\begin{array}{l}\text { Abdominal } \\
\text { perimeter }\end{array}$ & $\begin{array}{l}\text { Abdominal } \\
\text { perimeter }\end{array}$ & Body height & Body height & Body length & Body length \\
\hline Min & 23 & 23 & 21 & 20 & 32 & 13 \\
\hline Max & 45 & 45 & 34 & 41 & 53 & 59 \\
\hline Mean & 33.9 & 35.4 & 26.7 & 27.2 & 43.5 & 42.6 \\
\hline $\begin{array}{l}\text { Standard } \\
\text { deviation }\end{array}$ & 4.30 & 3.52 & 3.15 & 2.89 & 3.62 & 4.93 \\
\hline $\begin{array}{l}\text { Coefficient of } \\
\text { variation }\end{array}$ & 12.7 & 9.9 & 11.8 & 10.6 & 8.3 & 11.6 \\
\hline
\end{tabular}

\section{CONCLUSION}

Presence/absence of earlobes in the Peluca hen describe different body morphologies. As they are not due to an adaptative response, they could be related to body architecture rather than different ecotypes. The information to be gained in the study would be helpful especially in planning future breeding programs and conservation strategies of prospective local Guatemala hen population. Further studies involving morphometric, production and molecular analyses are important for exhaustive characterization. Such information will form a basis for conservation, selection and sustainable improvement strategies for the identified prospective local chickens. Creole hens play major role for the rural poor and marginalized section of the people with respect to their subsidiary income and also provide them with eggs and meat. This is why detailed knowledge of local breeds are needed to improve human nutrition and increase incomes.

\section{CONSENT}

The study involved taking body measurements from pigeons with the consent and in the presence of the breeders. The data was collected in fancies and animal owners agreed to be involved in the project (As there is no national specific legislation for body measurements, no approval was necessary. This study was carried out in live animals but with non-traumatic handling procedures, so no Ethics committee agreement was considered necessary).

\section{ACKNOWLEDGEMENTS}

Authors wish to thank to owners who kindly allowed the access to their animals and also to reviewers who contributed to the improvement of this article.

\section{CONFLICT OF INTERESTS}

Authors have no financial or personal relationships with other people or organizations that could inappropriately influence their work. We declare also there are no competing interests regarding the publication of this paper.

\section{REFERENCES}

1. N'dri AL, Fofana N, Okon AJL, AdepoGourene AB. Biometric characterization of local chicken 'Gallus gallus domesticus' according to the sex and phenotype from traditional breedings of Dabakala (Côte d'Ivoire). Int. J. Environ. Agric. Res. 2016; 2(3):1-6.

2. Donicer Montes V, de la Ossa J, Darwin Hernández H. Morphological characterization of the creole backyard chickens of the Subregion sabana department of Sucre (Colombia). Rev. MVZ Cordoba. 2019;24(2):7218-7224.

DOI: $10.21897 / \mathrm{rmvz} .1646$

3. Mbap ST, Okpanachi U. Phenotypic characterization of local chickens (gallus gallus domesticus) in Bekwarra Cross River State, Nigeria. JSM Vet. Med. Res. 2019;2(7):1-8.

4. FAO, Animal genetic resources conservation by management, data banks and training, FAO and UNEP, Rome; 1984.

5. Jáuregui $R$, Parés-Casanova PM. Presencia de tres biotipos en el gallo 'Peluca' de la región de Cho'Órti de Chiquimula, Guatemala. Actas Iberoam. Conserv. Anim. 2019;14:27-31.

6. Cabrera Gaitán AC. Caracterización de la 
avicultura de traspatio en 20 comunidades del cordón fronterizo Guatemala-México del Departamento de San Marcos. Universidad de Sant Carlos de Guatemala; 2011.

7. Corzo AR, Schwartz NB. Milpas y huertos de traspatio tradicionales en Petén, Guatemala y el problema de la seguridad alimentaria. Ciencias Soc. y Humanidades. 2016;3(2):7-24.

8. Palacios EY, Álvarez L, Muñoz J. Genetic diversity of Creole hens of the Colombian southwest. Arch. Zootec. 2016;65(249): 73-78,.

DOI: 10.21071/az.v65i249.444

9. Adekoya KO, Adefenwa MA, Ogunkanmi LA. Morphological characterization of five Nigerian indigenous chicken types. J. Sci. Res. Dev. 2013;14:55-66.

10. Muñoz T, Valarezo J, Vacacela $\mathrm{W}$, Guerrero R, Quezada A. Genetic variaBILity of the mitochondrial and nuclear dna in two generations of five biotipes of creole hens in the province of Loja. in Libro de Memorias del I Simposio de Investigación Científica de la Universidad Nacional de Loja. 2019;111122.

11. Mallia JG. Observations on family poultry units in parts of Central America and sustainable development opportunities. Livest. Res. Rural Dev. 1999;11:3.

12. Warren DC. Inheritance of earlobe color in poultry. Genetics. 1928;13:470-487.

13. Nie C. et al. Genome-wide association study revealed genomic regions related to white/red earlobe color trait in the Rhode Island Red chickens. BMC Genet. 2016;17(1):1-7.

DOI: 10.1186/s12863-016-0422-1

14. Guni FS,. Katuni AM. Characterization of local chickens in selected districts of the Southern Highlands of Tanzania: I. Qualitative characters. Livest. Res. Rural Dev. 2013;25(9).

15. Sañudo C, Valoración morfológica de los animales domésticos. Madrid: Minist. de Medio Ambiente y Medio Rural y Marino; 2009.

16. Francesch $A$, Villalba I, Cartañà $M$. Methodology for morphological characterization of chicken and its application to compare Penedesenca and Empordanesa breeds. Anim. Genet. Resour. génétiques Anim. genéticos Anim. 2011;48:79-84.

DOI: $10.1017 / \mathrm{s} 2078633610000950$

17. Hammer $\varnothing$, Harper DAT, Ryan PD. PAST v. 2.17c. Palaeontol. Electron. 2001; 4(1):1-229.

(c) 2021 Parés-casanova and Jáuregui; This is an Open Access article distributed under the terms of the Creative Commons Attribution License (http://creativecommons.org/licenses/by/4.0), which permits unrestricted use, distribution, and reproduction in any medium, provided the original work is properly cited.

Peer-review history:

The peer review history for this paper can be accessed here: http://www.sdiarticle4.com/review-history/61481 